\title{
Non-rhizomelic chondrodysplasia punctata
}

INSERM

\section{Source}

INSERM. (1999). Orphanet: an online rare disease and orphan drug data base. Nonrhizomelic chondrodysplasia punctata. ORPHA:176

Nonrhizomelic chondrodysplasia punctata is a form of chondrodysplasia punctata (see this term), a group of diseases in which the common characteristic is bone calcifications near joints from birth. Nonrhizomelic chondrodysplasia punctata is not an entity in itself but covers several diseases with variable clinical findings and modes of transmission. 